\title{
O SOFRIMENTO NO TRABALHO DOCENTE: O CASO DAS PROFESSORAS DA REDE PÚBLICA DE MONTES CLAROS, MINAS GERAIS
}

\author{
SUFFERING IN TEACHING:THE CASE OF THE PUBLIC NETWORK TEACHERS OF MONTES \\ CLAROS, MINAS GERAIS
}

Maria Márcia Bicalho Noronha ${ }^{1}$

Ada Ávila Assunção ${ }^{2}$

Dalila Andrade Oliveira ${ }^{3}$

Resumo Estudos nas últimas décadas têm evidenciado que o adoecimento do professor teria origem no paradoxo entre sua missão e a invisibilidade do trabalho docente aos olhos da organização escolar. O objetivo deste estudo é identificar possíveis interseções entre o excesso e rigor das cobranças, que não vêm acompanhadas das condições necessárias para a realização do trabalho do professor, e os relatos de frustração presente entre esses profissionais. Para avaliar o trabalho em sala de aula de nove professoras, adotou-se a metodologia da ergonomia da atividade de trabalho. Viu-se que as professoras, depois de intervirem inúmeras vezes para separar brigas de alunos em sala de aula, deixam, outras vezes, de dar atenção ao fato. Existe um momento em que elas ignoram a indisciplina, parecendo expressar uma estratégia para lidar com essa perturbação. Os resultados indicam a elaboração de um modelo de planejamento com previsão de tempo para as inúmeras atividades previstas pela nova missão da escola, visando a descongestionar a sala de aula e evitar a sobreposição de tarefas cuja marca mais intensa são as interrupções descritas.

Palavras-chave saúde e trabalho; ergonomia; professoras; sofrimento.
Abstract Studies in the last decades have shown that teachers' illnesses originate in the paradox between their mission and the invisibility of teaching in the eyes of the school organization. The objective of this study is to identify possible intersections between the excess and strictness of the demands, made without providing the conditions needed for the required teaching work, and the reports of frustration among those professionals. To assess the work of nine teachers in the classroom, the authors adopted the methodology of work activity ergonomics. It was found that the teachers, after intervening countless times to separate students fighting in class, at other times do not turn their attention to the fact. In such moments they ignore the lack of discipline, seemingly expressing a strategy to deal with the disturbance. The results indicate the preparation of a planning model with time estimates for the numerous activities established by the school's new mission, aiming to reduce crowding in the classroom and avoid the overlapping of tasks, which contribute markedly to the students' disruptions.

Keywords health and work; ergonomics; teachers; suffering. 


\section{Introdução}

É difícil pensar em modificar o processo educativo sem uma mudança concreta do processo de trabalho (Kohen, 2002), e a transformação necessária é um desafio por várias razões. Entre elas destaca-se, neste artigo, a separação que o sistema escolar faz entre trabalho docente e o processo pedagógico.

O trabalho do docente durante anos manteve-se invisível, por vezes escondido atrás da idéia da profissão como sacerdócio (Oliveira, 2003) ou das abordagens essencialistas, em que estão relacionados, linearmente, no entender de Carvalho (1999), a 'feminilidade' e os ideais de professora.

A constituição e o reconhecimento do trabalho docente como profissão foram marcados por importantes paradoxos. Se, por um lado, é visível o papel do/a professor/a no desenvolvimento social, por outro, as condições de trabalho precárias e a baixa remuneração oferecidas nas diferentes redes e níveis de ensino refletem o não reconhecimento ao trabalho docente. $\mathrm{Na}$ atualidade, assiste-se a um processo de desvalorização dessa profissão acompanhado da expansão das funções docentes. Múltiplas tarefas são atribuídas aos professores/as, pois, com a chegada da escola pública às camadas populares, o/a profissional tem de se responsabilizar por cuidar da higiene, da nutrição, da saúde e de outras necessidades dos seus alunos.

Nos anos 1990, o trabalho docente é reestruturado e, no movimento das reformas educacionais em curso na América Latina, para além das atividades em sala de aula e da ampliação das responsabilidades face ao aluno, o/a docente vai se ocupar também da gestão escolar, que inclui atividades de planejamento, elaboração de projetos, avaliação dos currículos (Oliveira, 2003).

No entanto, as reformas desconsideram o valor do papel do/a professor/a, mesmo, como lembra Cruz (2007), reconhecendo ser ele/a um sujeito fundamental para o processo de sua implementação. As políticas educacionais são elaboradas a distância e nem sempre estão conectadas às vivências do/a professor/a em sala de aula.

Via de regra, a gestão que os docentes operam na sala de aula para transpor os obstáculos que impedem ou reduzem o desempenho das tarefas é considerada numa perspectiva bastante restritiva pela gestão do sistema e pelos dirigentes do ensino.

Os resultados apresentados a seguir questionam a discrepância entre a organização do trabalho e a organização do sistema escolar. Os projetos educacionais têm se ocupado mais dessa última e do ensino centrado no saber e no desenvolvimento dos conteúdos, com ênfase para o aprimoramento dos recursos pedagógicos. O conhecimento sobre o trabalho docente, principalmente, no que se refere ao esforço empreendido pelos professores para executar os referidos projetos pedagógicos, ainda é pouco desenvolvido. 
Em relação às condições de trabalho, a situação é criticada pelos estudiosos no campo. Sem ajustar o efetivo ao número de alunos e ao volume de tarefas nas escolas, as novas demandas acabam se traduzindo numa intensificação do trabalho, pois em menor tempo o indivíduo terá de responder às múltiplas tarefas.

Nos últimos anos, os estudos epidemiológicos colocam em evidência a sobrecarga emocional derivada das exigências de investimentos pessoais dos professores em suas relações com alunos, pais dos alunos e comunidade (Jardim, Barreto e Assunção, 2007; Medeiros, Barreto e Assunção, 2006; Gasparini, Barreto e Assunção, 2006; Delcor, 2004; Reis et al., 2005).

A presença de obstáculos e as altas demandas no trabalho, incluindo as demandas emocionais, junto à falta de facilitadores e de recursos (Salanova, Llorens e Garcia-Renedo, 2003) podem explicar o mal-estar docente (Esteve, 1999), o burnout (Carlotto e Palazzo, 2006), os distúrbios psíquicos menores (Reis et al., 2005) e o estresse no grupo dos professores.

O sofrimento é uma noção fundamental ao campo da psicodinâmica do trabalho. Diz respeito ao espaço de liberdade que pode existir entre o ser humano e a organização do trabalho. Nesse espaço são possíveis a negociação e as invenções do trabalhador sobre a organização do trabalho na tentativa de adaptá-lo às suas necessidades. Nessa linha, o trabalho leva ao sofrimento, mas constitui-se também em fonte de prazer e de desenvolvimento humano (Dejours, 1993; 1987).

A insatisfação em relação ao conteúdo significativo da tarefa engendra o sofrimento mental, o qual pode fragilizar o indivíduo, tornando-o susceptível ao adoecimento. As manifestações sintomáticas variam desde um sentimento de insatisfação, frustração, chegando até uma angústia difusa e um profundo sentimento de culpa e impotência. O sofrimento é uma reação inconsciente à organização do trabalho, que surge quando a representação do trabalho é penosa, constituindo-se numa mediação entre a saúde mental e as descompensações psicopatológicas (Dejours, 1993).

O objetivo deste estudo é identificar possíveis interseções entre o excesso e rigor das cobranças que não vêm acompanhadas das condições necessárias para a realização do trabalho em sala de aula e as manifestações de sofrimento no grupo de nove professoras de uma escola pública.

\section{Sujeitos e período da pesquisa}

A pesquisa foi motivada pela experiência pessoal da primeira autora deste artigo, que trabalhou como professora durante 16 anos. Observava uma profunda insatisfação que se manifestava cotidianamente, por meio de queixas de esgotamento que poderiam estar na base de uma prevalência 
importante de absentismo no trabalho, objeto de vários debates na categoria e nas escolas.

Estudou-se uma escola pública que apresentava casos de absentismo por problemas de saúde conforme atestavam os dados da Secretaria de Educação. A escola foi selecionada por adesão à pesquisa após uma ampla negociação com os diretores. Situa-se em um bairro periférico de Montes Claros, Minas Gerais. Com 2.237 alunos nos três turnos de funcionamento, oferece salas para os ciclos inicial, intermediário e avançado. A população considera de boa qualidade o ensino oferecido, segundo os relatos em reuniões de pais.

As instalações são bastante precárias. As salas de aula são mal ventiladas e estão superlotadas. Nelas o mobiliário encontra-se em estado ruim de conservação, mesas e cadeiras usadas pelas professoras são inadequadas, e não existe espaço suficiente para os alunos e a professora se deslocarem.

O espaço externo também é pequeno, tendo em vista a população e, como o horário do recreio não é comum, o desconforto sonoro para os que permanecem trabalhando é constante. A cantina é exígua e não existe refeitório. As crianças lancham em pé ou sentadas pelo chão.

O trabalho de campo ocorreu entre março e junho de 2001, procurando-se participação ao máximo da vida da escola. Além da sala de aula, foram observadas uma reunião de conselho de classe, uma reunião de planejamento mensal e uma atividade festiva na escola.

O grupo estudado foi formado por nove professoras. A Tabela 1 apresenta as características do grupo quanto à idade, formação e tempo de serviço na docência, sendo uma delas do ciclo inicial e oito pertencentes ao ciclo intermediário. A diretora, a supervisora, a coordenadora da escola foram entrevistadas, visando a abordar as questões relativas à organização do ensino, às exigências atuais, ao planejamento do trabalho, à divisão de tarefas, ao perfil dos alunos.

Tabela 1

\begin{tabular}{lccc}
\multicolumn{2}{l}{ Características das professoras observadas em sala de aula } \\
\hline Professoras* & Idade & Formação & Tempo de serviço \\
\hline Eloísa & 37 anos & $3^{\circ}$ grau incompleto & 18 anos \\
Rosângela & 29 anos & $3^{\circ}$ grau completo & 6 anos \\
Edméia & 24 anos & $3^{\circ}$ grau completo & 5 anos \\
Alaíde & 36 anos & $3^{\circ}$ grau incompleto & 14 anos \\
Aparecida & 34 anos & $3^{\circ}$ grau incompleto & 6 anos \\
Marta & 31 anos & $3^{\circ}$ grau completo & 8 anos \\
Fátima & 30 anos & $3^{\circ}$ grau incompleto & 10 anos \\
Alice & 28 anos & $3^{\circ}$ grau incompleto & 9 anos \\
Patrícia & 39 anos & $3^{\circ}$ grau completo & 18 anos
\end{tabular}


O estudo foi aprovado pelo Comitê de Ética e Pesquisa da Universidade Federal de Minas Gerais. Os sujeitos estudados e a direção, após o conhecimento dos objetivos da pesquisa, concordaram em participar e assinaram o termo de consentimento livre e esclarecido. A seleção das nove professoras ocorreu por livre adesão após o convite que procurou obter uma amostra heterogênea dos participantes em relação à idade e ao tempo na escola.

\section{Construindo a investigação}

A investigação teve o propósito duplo de chegar a uma compreensão abrangente do grupo alvo e desenvolver declarações mais gerais sobre o processo de trabalho na escola estudada. A abordagem adotada supõe que se pode conhecer um fenômeno a partir da exploração intensa dos eventos observados e dos relatos dos sujeitos sobre os seus significados. Nessa direção, buscou-se responder as questões 'como' e 'por que' certos fenômenos ocorrem.

A natureza do objeto justificou a abordagem qualitativa a fim de compreender as situações de trabalho, tornando possível identificar elementos explicativos dos sintomas de cansaço e esgotamento relatados pelos professores na fase exploratória da pesquisa. Aos poucos, evidenciaram-se não só as condições reais de trabalho, situadas em um tempo e lugar bem definidos, como também a professora, com os seus valores, sentimentos, emoções e ainda as regras, a divisão das tarefas, as relações com os diferentes sujeitos da escola.

Adotou-se um modelo em espiral, no qual as etapas do processo de investigação não seguem um padrão rígido e predeterminado, mas reproduzem uma abordagem flexível tanto no processo em seu conjunto como na seqüência de passos a seguir (Mercado-Martinez e Bosi, 2004; AlvesMazzotti e Gewandsznajder, 1998).

Observando as ações, bem como as verbalizações das professoras em situação de trabalho, foi possível fazer uma aproximação da lógica interna da atividade. A análise do trabalho provoca a necessidade de distinguir tarefa de atividade. Recorrendo-se à teoria de Leontiev (1978), a atividade não pode existir senão pelas ações, constituindo-se pelo conjunto de ações subordinadas a objetivos parciais advindos do objetivo geral ou do resultado a ser alcançado. A tarefa é a meta a ser atingida e diz respeito às condições sob as quais essa meta será atingida. A atividade é aquilo que o trabalhador mobiliza de si mesmo para executar a tarefa. Todo trabalho mobiliza investimentos pessoais, pois o trabalho é cenário de construção de identidades por meio das vivências subjetivas e intersubjetivas que a atividade humana possibilita. 


\section{Procedimentos de coleta e análise de dados}

A observação da sala de aula dá acesso a uma ampla gama de informações, cuja existência o investigador pode não ter previsto no momento em que começou a estudar (Vasconcelos, 2002) e, portanto, é um método bem adequado aos propósitos do estudo das professoras. Foram adotadas as técnicas de investigação da escola francesa da ergonomia da atividade, a qual considera a distinção entre 'o que' foi estabelecido para os trabalhadores executarem e 'como' eles respondem às exigências do trabalho (Guérin et al., 2001).

As observações das aulas ministradas pelas professoras selecionadas originaram o diário de campo da pesquisa específica para cada professora. Os diários foram analisados tendo como foco as ações corporais (deslocamentos e gestos) e verbais (comunicações entre os atores na sala de aula) e serviram para elaborar duas variáveis de observação: reprimendas e interrupções. A duração da observação variou para cada professora.

As reprimendas referem-se às situações em que a professora censurou, com palavras 'enérgicas', o aluno, tocando-o ou dirigindo-se a ele, de forma bem próxima, repreendendo-o e buscando sua atenção e concentração nos conteúdos trabalhados. As interrupções externas designam os momentos de ruptura da atividade da professora em função da chegada de uma pessoa externa à sala de aula.

Uma vez que a atividade não pode ser reduzida ao que se consegue observar (Assunção e Lima, 2003), a etapa da autoconfrontação dos resultados das entrevistas e observações, estratégia que busca na palavra do trabalhador compreender os sentidos que ele próprio imprime aos resultados obtidos pelo pesquisador, permitiu aceder aos aspectos não-objetiváveis do trabalho.

O risco de provocar alterações no comportamento dos indivíduos observados foi atenuado pela permanência prolongada da pesquisadora no campo, a qual procurou uma aproximação com os sujeitos a fim de apresentar os objetivos pretendidos e estabelecer elos de confiança, como propõem Assunção e Lima (2003) e Vasconcelos (2002).

Durante as observações do trabalho desenvolvido em sala de aula pela professora, foram registradas as verbalizações dirigidas a ela, e vice-versa, e à pesquisadora (verbalização simultânea), na forma em que ocorreram. Nessa direção, foi possível identificar comportamentos não-intencionais ou inconscientes e explorar tópicos que as trabalhadoras dificilmente apresentariam fora do contexto temporal-espacial da situação de trabalho, conforme salientam Assunção e Lima (2003) e Abrahão (2002). Foram 37 horas e 15 minutos de observação. 
As observações gerais do funcionamento da escola e as observações das tarefas em sala de aula foram seguidas de entrevistas semi-estruturadas, visando ao melhor conhecimento da organização da escola, com ênfase nos eventos marcantes ocorridos em sala de aula, provocando uma reflexão pela professora sobre as suas ações e a explicitação das razões de seu comportamento. As professoras falaram livremente dos incidentes em sala de aula, das estratégias utilizadas para contorná-los e dos sentimentos vividos. Ao todo, oito horas e 30 minutos de entrevista. Cada entrevista durou, em média, 50 minutos. Foram gravadas e posteriormente transcritas e analisadas.

Não foi utilizada a metodologia desenvolvida no campo da psicodinâmica do trabalho e, por isso, não foram abordados os processos defensivos, os quais dizem respeito às resistências psíquicas às agressões emanadas da organização do trabalho. A investigação focalizou a realidade dos fatos do trabalho e a descrição que as professoras fizeram do seu trabalho, enquanto, no campo da psicodinâmica, o interesse teria sido dirigido para a dimensão do comentário. Segundo Dejours (1993), o comentário inclui concepções subjetivas, interpretações e hipóteses sobre a dinâmica da relação vivenciada no trabalho. No entanto, as entrevistas em torno das vivências objetivas em sala de aula trouxeram à tona elementos subjetivos, os quais permitiram localizar a problemática do sofrimento e prazer no grupo das professoras estudadas.

\section{Procedimentos de tratamento e sistematização dos dados}

A organização dos dados das entrevistas e das observações foi um processo continuado, no qual se buscou identificar as dimensões das dificuldades enfrentadas pelas professoras em sala de aula, as quais foram relatadas ou observadas ao longo da pesquisa, descrevendo o significado que as próprias professoras lhes atribuíram. Apareceu em destaque, devido à recorrência e à relevância, o esforço empreendido pelas professoras para gerir a indisciplina, que é exacerbada nos momentos de interrupção da aula por eventos externos (Tabela 2). Numa etapa subseqüente, os resultados extraídos de uma primeira análise foram tratados a partir da pauta de temas que sobressaíram da leitura flutuante dos discursos das professoras entrevistadas e das verbalizações colhidas em situação e em autoconfrontação, tendo sido relevantes os temas relativos aos sentimentos de culpa, não reconhecimento pelo esforço empreendido e prazer obtido no trabalho. 


\section{As exigências do ato de ensinar e os sentimentos mobilizados}

A professora, apesar de não escolher a realidade com a qual vai trabalhar, é uma mediadora entre os problemas de educação e de responsabilidade social e o desenvolvimento individual. A professora lida com uma situação social, em que se somam aos problemas da escola as condições precárias de trabalho, os salários aviltantes e as carências físicas e emocionais de um público de alunos que expressam em sala de aula as suas vivências cotidianas externas à escola.

As professoras, em geral, buscam compreender e superar as inúmeras dificuldades que interferem no processo de aprendizagem das crianças. Para isso, elas reconhecem como fundamentais a relação de proximidade e a afetividade no ato de ensinar. Como se verá nos extratos das entrevistas, para elas seria inimaginável pensar em educar sem amor. O amor seria importante para compreender a criança de forma contextualizada, participar da vida da criança, fazê-la se sentir importante. Sobre isso, a professora Edméia afirma: "Então nós temos uma relação muito boa, no que se refere à questão afetiva, na questão da compreensão mesmo."

Ensinar com amor permite, segundo as entrevistadas, intervir de forma adequada para atenuar os problemas dos alunos, e, nas situações difíceis, que envolvem manter a disciplina na sala de aula, conter os alunos, mas com paciência e carinho. Nos seus dizeres:

“Eu sou muito ligada à família, eu vou na casa, ou então chamo o pai, quando vejo que eles não estão dando assistência (...) Então eu pego um amor maior, e vou atrás e procuro dar tudo de mim para poder ajudar aquela criança (...) Eu sei que às vezes sou dura, às vezes sou carinhosa (...) É muito difícil, os meninos de hoje, a disciplina (...) Para poder trabalhar com esta disciplina [indisciplina] é muito difícil, a gente tem que ser até psicóloga, é preciso ter um conhecimento maior" (professora Edméia).

Para o grupo estudado, amar é investir no aluno e inclui procurar a família, interessar-se pela realidade individual, orientar e tentar compreender a situação extraclasse que aflige a criança. Nessa mesma direção, a professora Alice comenta: “Professor tem que ser um pouco psicólogo... ter muita afetividade. Se não tiver afetividade, não consegue, porque os meninos já têm problemas."

Neves e Silva (2006, p. 72) entendem a relação afetiva que os professores estabelecem com os alunos como sendo fonte de prazer. Entretanto, advertem sobre o paradoxo no qual "amor e saturação emocional em relação aos alunos se impõem simultaneamente e sob conflito". A saturação emocional pode decorrer, como se verá mais adiante, das ações docentes que 
buscam recuperar a disciplina e estabelecer um clima de concentração para desenvolver a aula.

Talvez a nova missão da escola, preconizada pelas diretrizes das reformas, implique no fato de cada professora, em seu universo particular, assumir cada vez mais o cuidado infantil. Assim sendo, como a organização do trabalho docente poderia ser ajustada aos tempos das reformas educacionais que correm? Ou seja, o cuidado infantil poderia ser incorporado ao modelo pedagógico e configurar-se em uma das metas que estruturam as escolas ultrapassando o ideário do trabalho docente como sendo típico do script feminino?

A feminização do magistério é vista na presença maciça das mulheres neste setor, mas também, como salientam Neves e Silva (2006, p. 67), "por uma certa maneira - considerada feminina - de perceber e de exercer o magistério". Sob a ótica das relações de gênero, o funcionamento das salas de aula e os modos de exercer o magistério são construções históricas que destinam os lugares sociais de homens e mulheres. Para as autoras, a inserção das mulheres durante o século XIX no mercado de trabalho se deu em profissões que têm ou passaram a ter características similares às da esfera doméstica, por exemplo, o cuidado às crianças. As características do tipo paciência, destreza, atenção e cuidado, por serem consideradas típicas da natureza feminina, não são reconhecidas no âmbito institucional; sendo assim, não são valorizadas.

O discurso da professora Patrícia, ao contrário daquele da professora Alice, não incorporou o cuidado como sendo uma atribuição sua:

\footnotetext{
“Tem certos procedimentos, em sala de aula, que seria da competência de um psicólogo, de uma assistente social, e acham que o professor tem de estar preparado para tudo isso. O professor tem de exercer tudo isso sem ser preparado para isso, né? Então, estamos acumulando muitas funções (...) mas existe a exigência, e o professor tem de dar conta" (professora Patrícia).
}

A capacidade de cuidar não seria uma qualidade inata, pois, pelo menos para a professora Patrícia, haveria a necessidade de formação específica e de condições concretas para assumir o cuidado infantil. Para Neves e Silva (2006), a associação da natureza da docência com a afetividade feminina resulta da construção de um sistema simbólico, variável em cada contexto histórico-social. Na atualidade, entender o cuidado como sendo algo intrínseco às mulheres desincumbiria o sistema de oferecer as condições de trabalho para o exercício da docência.

Incorporar as condições de trabalho necessárias ao trabalho na sala de aula e abrir as vias para legitimar o cuidado como parte de uma prática profissional seriam assumir que cuidado pode ser praticado por homens e 
mulheres. Nesse caso, quais seriam as necessidades de homens ou mulheres docentes para desenvolver a sua prática no cotidiano da sala de aula?

Sobre a organização do trabalho nas escolas, vê-se uma distância entre os procedimentos pedagógicos delineados pela gestão e os procedimentos que as professoras implementam para responder aos desafios da sala de aula. Conforme elucida Cruz (2007, p. 194), “há uma distância significativa entre as propostas oficiais e o dia-a-dia das escolas e os dilemas que os professores enfrentam no encaminhamento de seu trabalho". A professora não é chamada a participar da definição de metas para a escola, nem sempre é ouvida no momento da definição das políticas para o setor, tornando irrealizável, nos dizeres de Kohen (2002), o discurso retórico do projeto neoliberal em educação.

Os resultados desta pesquisa reafirmam a idéia de Martínez (2003, p. 81), ao lembrar que "as escolas sobrevivem porque os professores, 'em suas salas de aula', com 'seus alunos', conhecem mais e melhor do que 'os que estão acima' como ensinar e dirigir uma escola; como lidar com escassos recursos e seguir ensinando".

Uma professora diz que sai da sala de aula arrasada, quando não consegue realizar o planejado. Ela ressalta que tudo o que acontece de errado em relação à aprendizagem é sempre culpa da professora:

“O aluno vem com todo tipo de problema de casa e acham que o professor tem de dar conta de tudo aquilo. Se o aluno perturba a aula e se o professor não consegue desenvolver as atividades, é porque o professor não tem domínio de sala. Se o menino é um aluno de determinada maneira, o professor tem culpa. Se o aluno não faz nada, o professor tem culpa. Então, sempre a culpa recai sobre o professor. Essas são barreiras que enfrentamos e que causam muita angústia, muita tensão, nos levam, muitas vezes, até a ficar frustradas no nosso trabalho" (Professora).

Aparece com força, nas entrevistas do conjunto das professoras, as afirmações sobre a indisciplina dos alunos que não querem nada, não querem saber de estudar e, mesmo assim, quando não têm um bom rendimento, a responsabilidade é da professora. O sistema atribui à professora os fracassos identificados, por exemplo, a falta de motivação do aluno. Nessa direção, afeta, como explicitado por Neves e Silva (2006), a auto-estima e a identidade profissional.

Surge, mais de uma vez, nas entrevistas, a postura da professora que se responsabiliza pela situação escolar. É plausível, nesse contexto, lembrar a crítica e o debate travado nos anos 1980 sobre a idéia de sacerdócio, messianismo e voluntarismo como fundamentos da prática de ensinar (Oliveira, 2003). 
As professoras estudadas por Neves e Silva (2006), à semelhança das professoras deste estudo, se disseram responsáveis pelo insucesso dos objetivos pedagógicos; elas não se acreditavam competentes para ter um bom desempenho. A ausência da competência desejável constitui-se em uma fonte de sofrimento psíquico. Foi possível observar que as professoras, depois de intervirem inúmeras vezes para separar brigas de alunos em sala de aula, deixam, outras vezes, de dar atenção ao fato. Ou seja, há um momento em que elas ignoram os eventos de indisciplina, parecendo expressar uma estratégia para lidar, no seu limite, com o cansaço e os seus efeitos. O aparente desligamento seria uma manifestação de sofrimento diante de uma situação que requereu à exaustão a sua energia.

Considerando-se incapaz de transformar as situações de constrangimento no trabalho, as quais são geradas pela inexistência de suporte social, técnico ou político, a professora poderá desenvolver a perda do interesse no que faz. A culpa mencionada pela professora parece indicar a manifestação de um sofrimento diante de uma realidade difícil. Para Dejours (1993), o sofrimento começaria quando a relação entre o indivíduo e a organização é bloqueada, quando o trabalhador utilizou ao máximo as faculdades intelectuais psicoafetivas, psicosensoriais e de adaptação. No caso deste estudo, como ilustram os exemplos da prática na sala de aula, há momentos de exaustão, como se verá adiante, após inúmeras tentativas de controlar e estabelecer o clima necessário para o transcurso da aula.

$\mathrm{Na}$ aula em que a professora trabalhava as datas históricas, ensinando a fazer a conversão de ano em século, os alunos conversavam muito. A professora interrompe o conteúdo por várias vezes, para tentar recuperar a tranqüilidade no ambiente. Interrompe o conteúdo e intervém para separar uma briga de dois alunos e, logo após, a aula foi interrompida novamente por uma funcionária e pela supervisora que solicita a presença da professora. Nesse intervalo, o tumulto aumentou; quando voltou, a professora tentou recuperar a ordem, repreendendo os alunos. Em seguida, iniciou o acompanhamento individual, passando de carteira em carteira e orientando os alunos nas dificuldades que apresentavam. Alguns alunos estavam totalmente dispersos, fazendo aviõezinhos de papel. A professora tomou os aviõezinhos e outros objetos dos alunos e os repreendeu. Um aluno discutiu com ela, que continuou andando pela sala, orientando, individualmente, a atividade e repreendendo alguns alunos. Deparando-se com as dificuldades dos alunos, vai até o quadro e retoma a explicação para o coletivo. Pediu a atenção dos alunos que continuavam dispersos. Alguns conversavam, outros cantavam, batiam nas carteiras, faziam piadas, poucos estavam atentos. Uma aluna estava recortando as páginas do livro, o que gerou certo tumulto. Alguns alunos acharam graça, outros discordaram e chamaram a professora. Ela interveio e tomou o livro da aluna. Alunos e 
professora discutiram sobre a utilização do livro na sala de aula. Neste momento, a aula foi interrompida novamente por um evento externo.

Em seguida, a professora continua indo de carteira em carteira, dando o visto nos cadernos e fazendo anotações. A professora estava visivelmente irritada e, por repetidas vezes, voltou-se para tentar obter a disciplina dos alunos. Foi novamente chamada à porta, sendo interrompida pela terceira vez. Rapidamente a professora retornou e continuou a correção, sempre convidando os alunos a participarem. Os alunos respondiam qualquer coisa, como se estivessem brincando, e a professora ficava cada vez mais irritada. Na seqüência, a professora discutiu com dois alunos e solicitou a eles que se retirassem da sala. Os alunos saíram chutando as carteiras.

As situações vivenciadas pela professora observada indicam a falta de limites dos alunos. Carloto e Palazzo (2006) esclarecem sobre o desrespeito desses alunos aos direitos dos outros personagens do ambiente escolar e sobre a inversão completa do poder em que os alunos passam a controlar as situações em sala de aula, conforme ilustram as situações observadas neste estudo.

A professora queixa-se da necessidade de ser muito enérgica e de funcionar na base de gritos para obter o controle da disciplina, pois não seria um comportamento coerente com a sua personalidade. Diz sentir-se angustiada ao sair da sala, e, chorando, completa: “Eu fiquei cinco horas aqui, para mim eu não vi resultado algum (...) você vê algum aluno aprender, crescer, mas não é aquela maioria..."

Para Dejours (1993), as frustrações resultantes de um conteúdo significativo inadequado às potencialidades e às necessidades da personalidade podem provocar esforços de adaptação que nem sempre ficam na linha do tolerável para a saúde mental.

Em uma das sessões de observação, a professora apresentava o livro de história e explicava, na seqüência, sobre o 'Dia D'. Nesse dia, seriam distribuídos os livros para os alunos e um membro da família se dirigia à escola e assumia a responsabilidade pelos livros emprestados. Viu-se que a retomada do curso da aula é custosa para a professora, pois os alunos comentam o evento, explicitando as dúvidas que ele suscitou. Enfim, como seria esperado, ocorre uma dispersão em face do movimento provocado. Os alunos expõem suas dúvidas: 'O irmão pode vir no lugar dos pais?' ‘O que acontecerá caso o livro seja extraviado?'

A professora retoma o conteúdo de história e inicia a exposição sobre o tema Descobrimento do Brasil e logo começa a verificar a tarefa de casa, olhando os cadernos e dando visto. Novamente a aula foi interrompida, agora pela vice-diretora, que veio informar sobre a festa junina, lembrando a importância da participação dos pais. Os alunos ficaram muito agitados com a informação. A professora os repreendeu, demonstrando maior irritação. 
Dois outros alunos brigavam no fundo da sala e a professora não mais interveio e continuou com o conteúdo, mas sempre tentando atrair a atenção dos alunos dispersos. Termina rapidamente e retoma o conteúdo anterior quando é interrompida por uma funcionária, que veio se informar sobre o número de alunos a fim de planejar o almoço. O trabalho torna-se intenso e cansativo, como indicam as múltiplas atividades desempenhadas, as quais foram citadas acima.

O cenário atual, em que as reformas curriculares não vêm acompanhadas das condições objetivas de trabalho (por exemplo, disponibilidade de mapas, livros, materiais e artefatos para elaboração de painéis, salas de vídeo, espaços para trabalhos em grupo etc.), obstaculiza a professora na escolha dos modos operatórios segundo as necessidades da criança que ela diagnostica em tempo real.

Na aula sobre os primeiros habitantes do Brasil, como viviam e como se alimentavam, a professora Patrícia explicava: "Os primeiros habitantes se alimentavam de raízes (...) e, hoje, nós nos alimentamos de raízes? (...) Sim. Quais as raízes?" Alguns alunos responderam "cebolinha, laranja...". A professora pergunta: "Laranja é raiz?" Um aluno se precipita: "Laranja-daterra (...) Laranja-da-terra é raiz." A professora, com visível irritação, quis saber: "Gente, o que é uma raiz?" Ninguém respondeu. A professora comentou em voz baixa com a pesquisadora: "Não é possível saber se eles não sabem ou se erram de propósito." O diálogo descrito ilustra uma queixa bastante freqüente nas entrevistas, que se refere ao comportamento jocoso do aluno.

Enquanto tentava cuidar da confusão que parecia uma zombaria, iniciase uma briga entre dois alunos e a professora foi chamada a intervir. No momento seguinte, outra briga acontece e, novamente, a professora intervém para separar os alunos. Em seguida, ela retomou o conteúdo da aula.

Os eventos externos, no transcurso da aula, são rupturas temporais que trazem atividades concorrentes àquelas que o professor está desenvolvendo num dado momento. Na primeira aula observada (uma hora de observação sistemática), a professora Patrícia fez 19 reprimendas e foi interrompida três vezes. Na segunda aula (uma hora e 25 minutos de observação sistemática), fez 49 reprimendas e a atividade foi interrompida quatro vezes por agentes externos à sala de aula. A Tabela 2 apresenta o número de reprimendas e de interrupções em cada aula observada. Depreende-se a importância desses eventos para a gestão da sala de aula a cargo da professora em suas tentativas de contornar as situações de dispersão e o grau de esforço por ela mobilizado. 
Tabela 2

\begin{tabular}{|c|c|c|c|c|}
\hline Professoras* & Data & Tempo observado & $\mathrm{N}^{\circ}$ de reprimendas & Interrupções \\
\hline \multirow[t]{2}{*}{ Patrícia } & $18 / 06 / 01$ & $1 \mathrm{~h}$ & 19 & 3 \\
\hline & $20 / 06 / 01$ & $1 \mathrm{~h} 25 \mathrm{~min}$ & 49 & 4 \\
\hline \multirow[t]{3}{*}{ Eloísa } & $22 / 05 / 01$ & $1 \mathrm{~h} 25 \mathrm{~min}$ & 31 & 3 \\
\hline & $28 / 05 / 01$ & $3 \mathrm{~h} 30 \mathrm{~min}$ & 55 & 11 \\
\hline & $29 / 05 / 01$ & 1h $45 \mathrm{~min}$ & 15 & 5 \\
\hline \multirow[t]{2}{*}{ Rosângela } & $30 / 05 / 01$ & $40 \mathrm{~min}$ & 13 & 1 \\
\hline & $13 / 06 / 01$ & $2 \mathrm{~h} 5 \mathrm{~min}$ & 31 & 1 \\
\hline \multirow[t]{3}{*}{ Marta } & 04/06/01 & $50 \mathrm{~min}$ & 37 & 1 \\
\hline & 05/06/01 & 1h 35 min & 43 & 6 \\
\hline & $18 / 06 / 01$ & $50 \mathrm{~min}$ & 24 & 1 \\
\hline \multirow[t]{3}{*}{ Aparecida } & $04 / 06 / 01$ & $40 \mathrm{~min}$ & 5 & 1 \\
\hline & $05 / 06 / 01$ & 1h $30 \mathrm{~min}$ & 16 & 4 \\
\hline & $18 / 06 / 01$ & $1 \mathrm{~h} 10 \mathrm{~min}$ & 12 & 2 \\
\hline \multirow[t]{2}{*}{ Edméia } & $07 / 06 / 01$ & $1 \mathrm{~h} 25 \mathrm{~min}$ & 18 & 3 \\
\hline & $11 / 06 / 01$ & $2 \mathrm{~h} 55 \mathrm{~min}$ & 10 & 4 \\
\hline Fátima & $12 / 06 / 01$ & 1h $30 \mathrm{~min}$ & 11 & 4 \\
\hline Alaíde & $25 / 06 / 01$ & $3 \mathrm{~h} 30 \mathrm{~min}$ & 29 & 6 \\
\hline
\end{tabular}

Fonte: as autoras.

* Os nomes são fictícios.

Os eventos externos não interessam, necessariamente, ao conjunto da turma e o lapso temporal é ocupado diversificadamente por cada um dos membros do grupo. A professora terá dificuldades, como notado, para reencaminhar o coletivo de alunos à atividade anterior à entrada do agente externo à sala. As interrupções geram uma sobrecarga, pois retomar as informações que estavam sendo tratadas depois de lidar com a demanda insurgida (o caso de um agente externo que traz um assunto alheio ao tema tratado pela professora) requer da professora mobilizar informações estocadas recentemente em sua memória, e, por isso, mais frágeis, necessitando de mais atenção e esforço mental.

Em suma, no transcurso das aulas da professora Patrícia, os eventos que se sobrepõem concorrem com a atividade diretamente relacionada ao conteúdo que está sendo trabalhado. Os eventos dizem respeito ao novo papel da escola e ao perfil do seu aluno e podem trazer conseqüências sobre a saúde do professor no caso de a organização não prover a escola dos instrumentos e dos métodos ajustados às exigências das tarefas. 
A professora Edméia lembra a sua ênfase junto aos alunos sobre as razões das reprimendas. Explica que, quando chama a atenção para os erros que cometem, ela o faz porque gosta deles. Diz ainda que entendem isso e que mantém com eles uma relação de carinho e amorosidade. A professora tem orgulho de seus alunos: "Você vê pelas respostas, tem menino que dá respostas muito maduras. Coisas que a gente pergunta e eles conseguem ir além, dando respostas inteligentes, você vê que a pessoa parou para raciocinar aquilo ali."

No pólo prazer da dinâmica 'prazer-sofrimento', a professora Edméia fala do seu entusiasmo ao ver o envolvimento do aluno nas atividades: “Eu gosto de ver o interesse do aluno, às vezes eu peço para o aluno recortar alguma coisa, e ele chega e diz: 'eu não tinha isso para recortar, mas eu desenhei.' Aquele empenho do aluno, isso me alegra, ele chega e diz: 'Ó, tia, eu não estou sabendo isto, a senhora pode me ajudar?'” Assim, a professora fala do seu prazer e da sua alegria diante do interesse do aluno.

As professoras reconhecem a importância e a responsabilidade da profissão: "Se você é um péssimo professor, o aluno vai ser um péssimo aluno. Então, eu cobro o máximo, eu sou exigente, mas dou oportunidade de fazer de novo. Eu acho que o aluno tem de ter responsabilidade, e eu tenho de dar os meios para ele conseguir chegar a algum lugar."

Diante das novas exigências do sistema de ensino; da cobrança cada vez maior da comunidade; do perfil dos alunos, cada dia mais indisciplinados; e do processo competitivo dentro da própria escola, a professora busca superar suas dificuldades e se adaptar às exigências do novo padrão organizacional. A professora Eloísa desabafa:

“É muito difícil trabalhar a questão da disciplina, às vezes até tem que dar uma parada, senão você perde o controle (...) é muito difícil, os meninos de hoje (...) trabalhar com essa disciplina é muito difícil (...) tem que ter um conhecimento maior, que eu não tenho, para lidar com essas crianças. Eu converso com outras pessoas, pergunto, leio revistas sobre o assunto, mas ainda é pouco" (professora Eloísa).

Frente à distância existente entre as exigências e as condições reais de trabalho, a professora elabora suas próprias estratégias, ou, nos seus dizeres, "dá o seu jeito", visando atender aos objetivos propostos. As situações de regulação da carga de trabalho intra e extraclasse são indícios de uma elaboração afirmativa de sofrimento e de prazer, conforme já assinalado por Neves e Silva (2006).

Em relação ao descanso semanal, a professora Eloísa relata que organiza o seu final de semana de forma a descansar física e mentalmente, ou seja, 
implementa uma estratégia para lidar com o cansaço, repor energias e se preparar para a continuidade do trabalho.

A professora Aparecida busca conciliar o volume de trabalho com o lazer e, dessa forma, não abre mão de nada, mesmo que tenha de levar junto algum trabalho para fazer, como é o caso da correção de provas: "No final de semana, na hora da cervejinha sento no barzinho, com prova, corrigindo, tomo minha cervejinha, não atrapalha." A professora desenvolve uma versatilidade digna de nota: toma cerveja, usufrui da companhia dos amigos e trabalha, tudo ao mesmo tempo.

Uma professora relata que sua estratégia é fugir da rotina, o elemento surpresa ajuda a prender a atenção dos meninos, segundo ela. E ensina: "Procuro diversificar, eu nunca deixo que os alunos saibam com antecedência o que vou trabalhar." A mesma professora, em outro momento, diz que o planejamento prescrito nem sempre é o melhor para os alunos e que, por vezes, pode contribuir para aumentar os problemas de aprendizagem deles. Dessa forma, relata que costuma fugir dos planos pedagógicos prescritos: "Eu acho que a professora tem de ter liberdade dentro da sala de aula para se expressar, para poder buscar formas mais prazerosas. Porque, às vezes, o aluno não aprende, exatamente porque não está prazeroso para ele."

As professoras se ressentem da falta de reconhecimento pelo investimento pessoal para dar conta dos desafios da sala de aula e das metas das reformas, nem sempre compatíveis com as condições existentes. Nos dizeres da professora Fátima: “A gente está ali na frente, comandando como se fosse um trem, a gente ali na frente guiando aquele trem e os alunos como se fossem os vagões... então, eu sei que somos as grandes responsáveis pela educação, mas só que, nem sempre, somos valorizadas."

A professora procura o reconhecimento dos pais, dos alunos, dos pares e da hierarquia e, na maior parte das vezes, não encontra. A professora prepara-se, estuda, faz um planejamento, investe tempo e energia, então ela quer ter o reconhecimento pelo trabalho realizado. A professora Alaíde diz não compreender como uma profissão tão bonita pode ser tão desvalorizada. Ao dizer isso, ela se refere também aos baixos salários. São condições, segundo Dejours (1993), favoráveis ao sofrimento.

As vivências descritas não passam incólumes para a economia psíquica. O trabalho é um operador da saúde mental, desde que as contribuições coletivas e singulares à organização do trabalho possam ser objeto de uma retribuição simbólica. Trata-se, na teoria da psicodinâmica do trabalho (Dejours e Molinier, 1994), do reconhecimento pelo trabalho realizado.

Às exigências, as professoras respondem com a necessidade de estudar, de se informar e relatam que, além do trabalho em sala de aula, é preciso ter tempo extra para planejar e preparar a aula. A professora afirma: "Já fiz muitos cursos, hoje procuro ler mais, apesar do salário ser pouco, eu 
procuro e, quando dá, eu compro livro, revista, para ficar bem informada. Atualmente estou fazendo faculdade." Uma professora relata que se ocupa "praticamente o dia todo, porque, na hora de planejar, você tem de ler muito, tem de estudar".

As professoras sentem-se exigidas, cobradas e, muitas vezes, sem respostas para as novas demandas apresentadas pelo planejamento, pela comunidade e pelos alunos. A professora Alice comentou a esse respeito, dizendo:

\footnotetext{
“Eu preciso de um tempo de estudo, é atualização, é de troca de experiência. Eu estou sempre buscando, porque eu sei como que é sacrificante ficar quatro horas na sala de aula com crianças e tudo, a gente deve estar sempre procurando uma melhor maneira de passar o conteúdo, dos meninos se interessarem pelo conteúdo" (professora Alice).
}

Dessa forma, a necessidade de qualificação aparece com muita força e, apesar de ser vista como a saída para alguns desafios da educação brasileira, não são garantidas aos professores as condições para o aprimoramento didático-pedagógico (Gasparini, Barreto e Assunção, 2006). Referindo-se às dificuldades enfrentadas diante da necessidade de voltar a estudar, a professora Fátima, que acabou de passar no vestibular, expressa o seu sentimento: "Para mim, o início foi assustador, nem fiquei muito contente quando fui aprovada, não, porque vou ter que abrir mão de tanta coisa... Vou ter que arranjar uma maneira de conciliar tudo e não me estressar, nem ficar nervosa." Oliveira (2003), ao criticar a noção de competência que norteia, atualmente, os planos para a formação dos professores, lembra que o número de certificados e de diplomas que o professor possui são mais valorizados do que a relação com os seus alunos ou os seus colegas.

Não se sentindo segura, não compreendendo a natureza dos problemas apresentados e diante de intensas cobranças, é, talvez, mais fácil para a professora tomar para si a responsabilidade em procurar os recursos para garantir a qualificação tão almejada. E, conforme seus relatos, de alguma forma, maiores conhecimentos, se não diminuem os problemas, pelo menos ajudam a melhor compreender os seus determinantes. Sobre o tema, é ilustrativo o depoimento da professora Eloísa, que, depois de 18 anos de trabalho, voltou a estudar e está fazendo faculdade: "Agora eu comecei a ver as coisas com mais clareza (...) estou entendendo mais meus alunos, eu estou tendo mais meios, mais condições."

Mas é importante resgatar que, nos caminhos da qualificação, os professores guiados pela noção de competência mobilizam, por seus próprios meios, os mecanismos para aprimorar o desempenho no trabalho e terminam muito insatisfeitos (Oliveira, 2003). Essa autora convida a uma reflexão 
sobre a origem da insatisfação, localizando elementos no descompasso, para reproduzir os seus termos, entre a prescrição dos programas de reformas e programas de formação de professores e os meios oferecidos para a realização do trabalho.

\section{Considerações finais}

O movimento que emana do microtexto da sala de aula poderia, nos dizeres de Cruz (2007), representar o caminho mais viável para a consolidação de mudanças educacionais. Ao contrário, no modelo educacional vigente, a vida prática docente continua invisível para o sistema escolar (Oliveira, 2000).

As interrupções tanto de origem externa quanto interna à sala de aula explicam a irritação da professora. Se a escola expandiu as suas funções, por que não estabelecer meios para um ambiente menos tumultuado e mais confortável, considerando o perfil do aluno que chega até ela?

Nessa direção, é lúcido pensar um modelo de planejamento com previsão de tempo para as inúmeras atividades previstas pelos novos objetivos da escola visando a descongestionar a sala de aula e evitar a sobreposição de tarefas cuja marca mais intensa são as interrupções descritas.

Os sentimentos de frustração, de culpa, de não reconhecimento são expressos pelas professoras junto aos relatos de tentativas de compensação para o esforço empreendido. Contudo, elas conseguem implementar modos operatórios particulares visando a regular as perturbações, as múltiplas tarefas concorrentes entre si, e salientam as vivências de prazer face ao crescimento do aluno. Para driblar as situações nocivas, foram vistas as estratégias de divisão do tempo entre trabalho, descanso e lazer que dependem da capacidade de fazer diferentes coisas ao mesmo tempo - trabalhar, divertir-se, usufruir a companhia de outras pessoas, cuidar dos afazeres domésticos...; mas, também, uma postura de indiferença quando os seus próprios limites se esgotam, configurando-se numa situação de sério risco sobre a sua auto-estima e proteção de sua saúde.

Embora não tenha sido possível explorar os processos defensivos, as manifestações subjetivas indicam a coexistência de prazer e sofrimento no trabalho docente. Compreender o trabalho tendo como foco a ação situada em sala de aula trouxe elementos explicativos para os problemas de cansaço e esgotamento e afastamentos também descritos na literatura consultada.

Na concepção de Martínez (2003), há risco de adoecimento quando está presente a sensação do inacabado. O desamparo ao qual se vê isolada na sala de aula estaria ligado às vivências subjetivas negativas, as quais têm relação com o adoecimento da professora. 
Os resultados apresentados contribuíram para diminuir a carência, mencionada por Noronha (2001) e por Martínez (2003), de estudos específicos relacionados com o trabalho da professora e de seu lugar de atuação, a sala de aula, a qual se situa entre as diretrizes da escola e as do sistema de ensino.

\section{Notas}

1 Professora da Universidade Estadual de Montes Claros (Unimontes), Montes Claros, Minas Gerais, Brasil. Mestre em Saúde Pública pela Universidade Federal de Minas Gerais (UFMG).<mmbicalho@unimontes.br>

Correspondência: Campus Universitário Professor Darcy Ribeiro, Centro de Ciências Humanas (CCH), Prédio 2, Departamento de Educação, Caixa Postal 126, Montes Claros, Minas Gerais, Brasil, CEP 39401-089.

2 Pesquisadora do CNPq e professora do Programa de Pós-Graduação em Saúde Pública da Faculdade de Medicina da Universidade Federal de Minas Gerais (UFMG), Belo Horizonte, Minas Gerais, Brasil. Doutora em Ergonomia pela École Pratique Des Hautes Études (EPHE), França. <adavila@medicina.ufmg.br>

3 Pesquisadora do CNPq e professora Associada da Universidade Federal de Minas Gerais (UFMG), Belo Horizonte, Minas Gerais, Brasil. Pós-doutora pela Université de Montréal, Canadá, e pela Universidade do Estado do Rio de Janeiro (Uerj). <dalila@fae.ufmg.br>

\section{Referências}

ABRAHÃO, Júlia I. As transformações do trabalho e desafios teórico-metodológicos na ergonomia. Estudos de Psicologia, Natal, v. 7, p. 745-752, 2002.

ALVES-MAZZOTTI, Alda J.; GEWANDSZNAJDER, Fernando. O método nas ciências naturais e sociais: pesquisa quantitativa e qualitativa. São Paulo: Pioneira, 1998.

ARAÚJO, Tânia Maria et al. Saúde e trabalho docente: dando visibilidade aos proces- sos de desgaste e adoecimento docente a partir da construção de uma rede de produção coletiva. Dossiê: trabalho docente. Educação em Revista, Belo Horizonte, v. 37, p. 183-212, 2003.

ASSUNÇÃO, Ada A.; LIMA, Francisco Paula A. A contribuição da ergonomia para a identificação, redução e eliminação da nocividade do trabalho. In: MENDES, René (Org.). Patologia do trabalho. 2. ed. São Paulo: Atheneu, v. 2, p. 1.767-1.789, 2003. 
CARLOTTO, Mary S.; PALAZZO, Lílian S. Síndrome de burnout e fatores associados: um estudo epidemiológico com professores. Cadernos de Saúde Pública, Rio de Janeiro, v. 22, n. 5, p. 1.017-1.026, 2006.

CARVALHO, Marília P. A história de Alda: ensino, classe, raça e gênero. Educação $e$ Pesquisa, São Paulo, v. 25, n. 1, p. 89-106, 1999.

CODO, Wanderley (Org.). Educação: carinho e trabalho. Petrópolis: Vozes, 1999.

CRUZ, Giselle B. A prática docente no contexto da sala de aula frente às reformas curriculares. Educar, Curitiba, n. 29, p. 191205, 2007.

DEJOURS, Christophe. Travail usure mentale: de la psychopathologie à la psychodynamique du travail. Paris: Bayard Éditions, 1993.

DEJOURS, Christophe; MOLINIER, Pascale. Le travail comme énigme. Sociologie du travail, Paris, v. 2, p. 35-44, 1994.

DEJOURS, Christophe. Plaisir et souffrance dans le travail. Séminaire interdisciplinaire de psychopathologie du travail. Paris: Éditions Centre Nacional de la Recherche Scientifique, 1987.

DELCOR, Núria S. et al. Condições de trabalho e Saúde dos professores da rede particular de ensino de Vitória da Conquista, Bahia, Brasil. Cadernos de Saúde Pública, Rio de Janeiro, v. 20, n. 1, p. 187-203, 2004.

ESTEVE, José Manuel. Malestar docente. Barcelona: Paidós, 1999.

GASPARINI, Sandra Maria; BARRETO, Sandhi Maria; ASSUNÇÃO, Ada A. Prevalência de transtornos mentais comuns entre professores da rede municipal de ensino de Belo Horizonte. Cadernos de Saúde Pública, Rio de Janeiro, v. 22, n. 12, p. 2.679-2.691, 2006.
O professor, as

condições de trabalho e os efeitos sobre sua saúde. Educação e Pesquisa, São Paulo, v. 31, n. 2, p. 189-199, 2005.

GODOY, Arilda S. Pesquisa Qualitativa: tipos fundamentais. Revista de Administração de Empresas, São Paulo, v. 35, n. 3, p. 20-29, 1995.

GUÉRIN, François et al. Compreender o trabalho para transformá-lo. São Paulo: Edgard Blücher, 2001.

JARDIM, Renata; BARRETO, Sandhi Maria; ASSUNÇÃO, Ada A. Condições de trabalho, qualidade de vida e disfonia entre docentes. Cadernos de Saúde Pública, Rio de Janeiro, v. 23, n. 10, p. 2.439-2.461, 2007.

KOHEN, Jorge A. Epidemiología del sector docente. In: PANAIA, Marta (Org.). Competitividad y salud ocupacional. Buenos Aires: Editorial La Colmena, p. 203-220, 2002.

MARTÍNEZ, Deolidia. El proceso de trabajo en el sector docente. In: PANAIA, Marta (Org.). Competitividad y salud ocupacional. Buenos Aires: Editorial La Colmena, p. 193201, 2002.

Estudos do trabalho docente. In: OLIVEIRA, Dalila A. (Org.) Reformas educacionais na América Latina e os trabalhadores docentes. Belo Horizonte: Autêntica, p. 7585, 2003.

MEDEIROS, Adriane M.; BARRETO, Sandhi Maria; ASSUNÇ̃̃O, Ada A. Professores afastados da docência por disfonia: o caso de BH. Cadernos Saúde Coletiva, Rio de Janeiro, v. 14, n. 4, p. 615-624, 2006.

MERCADO-MARTINEZ, Francisco J.; BOSI, Maria Lúcia M. Introdução. Notas para um debate. In: Pesquisa qualitativa de serviços de saúde. Petrópolis: Vozes, 2004.

NEVES, Mary Y.R.; SILVA, Edith S. A dor e a delícia de ser (estar) professora: trabalho 
docente e saúde mental. Estudos e Pesquisas em Psicologia, Rio de Janeiro, v. 6, n. 1, p. 63-75, 2006.

NORONHA, Maria Márcia B. Condições do exercício profissional da professora e dos possiveis efeitos sobre a saúde: estudo de casos das professoras do Ensino Fundamental em uma escola pública de Montes Claros, Minas Gerais. Dissertação de mestrado apresentada ao Programa de Pós-Graduação em Saúde Pública, Mestrado da Faculdade de Medicina, UFMG, Belo Horizonte, 2001.

OLIVEIRA, Dalila A. As reformas educacionais e suas repercussões sobre o trabalho docente. In: Reformas educacionais na América Latina e os trabalhadores docentes. Belo Horizonte: Autêntica, p. 13-35, 2003.
OLIVEIRA, Dalila A. Educação básica: gestão do trabalho e da pobreza. Petrópolis: Vozes, 2000.

REIS, Eduardo José F.B. et al. Trabalho e distúrbios psíquicos em professores da rede municipal de Vitória da Conquista, Bahia, Brasil. Cadernos de Saúde Pública, Rio de Janeiro, v. 21, n. 5, p. 1.480-1.490, 2005.

SALANOVA, Marisa; LLORENS, Susana; GARCIA-RENEDO, Mônica. ¿Por qué se están 'quemando' los profesores?. Revista del Instituto Nacional de Seguridad e Higiene en el Trabajo, Madri, n. 28, p. 16-20, 2003.

VASCONCELOS, Eduardo M. Complexidade e pesquisa interdisciplinar: epistemologia e metodologia operativa. Petrópolis: Vozes, 2002.

Recebido em 26/08/2006

Aprovado em 01/03/2008 